\title{
Acknowledging growth and success rooted in rubber research developments
}

\author{
Veronica Charlotte ${ }^{1} \cdot$ Charlotte Cross $^{2}$
}

Accepted: 20 September 2021 / Published online: 4 October 2021

(c) The Malaysian Rubber Board 2021

The ongoing efforts of the research community in this time of change and uncertainty are of the utmost importance, and worthy of admiration, as we continue to face the challenges posed by the ongoing pandemic throughout most of 2021. With the publication of this third issue of Volume 24, 2021, Journal of Rubber Research (JRUR) bids farewell to the outgoing Editor-in-Chief, Dr. Amir Hashim Md Yatim. We wish him every success in his new role as CEO of the International Rubber Consortium Limited (IRCo), based in Thailand. Dr. Amir was appointed Deputy Director General of Research and Innovation at Malaysian Rubber Board (MRB), and subsequently Editor-in-Chief of JRUR in 2018. His legacy and the highlights of his leadership include the growth of JRUR as a result of the collaboration and publishing partnership with Springer Nature in 2018, the journal's $90^{\text {th }}$ anniversary, and escalation of its impact factor (IF) ranking over 2019 and 2020, with a leap in the number of submissions accepted for publication contributing to the progressive increase in downloads and citations. Dr. Sunderasan Elumalai, MRB's Lead Principal Scientist (and JRUR Editorial Committee Member) has been appointed to replace Dr. Amir as interim Editor-in-Chief. Dr. Sunderasan is a prolific writer, having authored numerous journal research articles, book chapters and monographs. JRUR is very glad to welcome him.

Special Issues (SIs) are an exciting new development for JRUR, which plans to publish several themed issues in collaboration with subject matter experts and guest editors, from 2021 onwards. The publication of the very first SI entitled "New challenges and methods in the experimental investigation and modelling of elastomers", led by guest editors, Prof Dr. Michael Johlitz of University of the Bundeswehr Munich, and Prof Dr. Stefan Hartmann of Clausthal

\footnotetext{
Veronica Charlotte

veronica@lgm.gov.my

1 Malaysian Rubber Board, Kuala Lumpur, Malaysia

2 Springer Nature, London, UK
}

University of Technology, in Germany, was a great success. Upcoming SIs include Current Progresses in Rubber Technology with an emphasis on materials, composites and technology, led by respected Editorial Committee Member Dr. Manroshan Singh of MRB, and Dr. Muzafar Zulkifli of Universiti Kuala Lumpur. A couple of others in planning for 2022 include the Recent Advances in Rubber Research and Applications, in conjunction with the $1^{\text {st }}$ International Conference on Plantation Technology (ICPTech 2021) which will be held virtually from $23^{\text {rd }}$ to $24^{\text {th }}$ November, and another on Membrane Technology for the Rubber Industry.

Alongside these developments, JRUR is proud to highlight a significant rise in its IF ranking for 2020, from 0.353 in 2019 , to 0.667 . The 5 year IF also shows a significant increase, from from 0.393 in 2019 to 0.618 in 2020 . The journal is very grateful to our excellent authors who have made this possible, together with a team of eminent scientists and subject matter experts. Our reviewers and the members of the Editorial Board have as always contributed as gate keepers in their respective roles throughout the peer review process. MRB looks forward to continuing the positive trend of robust usage shown in the $144 \%$ increase in article downloads from 2019 to 2020, which in turn validates a growing readership as a result of more than a twofold upsurge in accepted and published articles throughout 2021. The present Issue 3, Volume 24 particularly, comprises 21 articles, the highest in comparison with previous issues throughout the journal's 90 over years of publication history.

Publisher's Note Springer Nature remains neutral with regard to jurisdictional claims in published maps and institutional affiliations. 